\title{
sciendo
}

Current Issues in Pharmacy and Medical Sciences

Formerly ANNALES UNIVERSITATIS MARIAE CURIE-SKLODOWSKA, SECTIO DDD, PHARMACIA

\section{The effects of pomegranate peel extract on recurrent aphthous stomatitis}

\author{
Sara Darakhshan ${ }^{1,2} \oplus$, Mohammad Malmir $^{3}$, Fereshteh Bagheri $^{2} \oplus$,

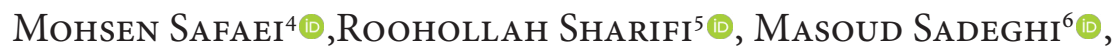

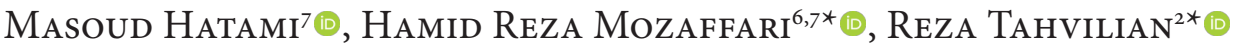

${ }^{1}$ Department of Biology, Faculty of Science, Razi University, Kermanshah, Iran

${ }^{2}$ Pharmaceutical Sciences Research Center, School of Pharmacy, Kermanshah University of Medical Sciences, Kermanshah, Iran

${ }^{3}$ Students Research Committee, Kermanshah University of Medical Sciences, Kermanshah, Iran

${ }^{4}$ Advanced Dental Sciences Research Laboratory, School of Dentistry, Kermanshah University of Medical Sciences, Kermanshah, Iran

${ }^{5}$ Department of Endodontics, School of Dentistry, Kermanshah University of Medical Sciences, Kermanshah, Iran

${ }^{6}$ Medical Biology Research Center, Kermanshah University of Medical Sciences, Kermanshah, Iran

${ }^{7}$ Department of Oral and Maxillofacial Medicine, School of Dentistry, Kermanshah University of Medical Sciences, Kermanshah, Iran

\section{ARTICLE INFO}

Received 15 August 2018

Accepted 11 March 2019

\section{Keywords:}

Antioxidant,

pomegranate peel extract,

recurrent aphthous stomatitis.

\begin{abstract}
As high as $20 \%$ of the population is thought to have recurrent aphthous stomatitis (RAS), hence, finding new therapeutic agents may be needed. Pomegranate (Punica granatum), has been extensively used in the folk medicine of many cultures, as it possesses antioxidant, anti-inflammatory and anti-bacterial properties. In this study, it is hypothesized that a topical form of pomegranate peel extract (PPE) may shorten the duration, accelerate the healing and reduce the pain of RAS patients. The presented randomized, doubleblind study was conducted on 56 patients. Herein, 28 patients were advised to apply PPE gel, and the other 28 patients were given placebo gel, twice daily for one week. Efficacy evaluations were made at days 0 (before using the gel), 3,5 and 7 . The mean values of ulcer size, pain and healing duration of ulcers were compared in both groups. PPE gel was significantly effective in reducing the pain $(\mathrm{p}<0.001)$, ulcer size $(\mathrm{p}<0.001)$, and healing duration of ulcers $(\mathrm{p}<0.001)$ over a period of one week. PPE in the form of oral gel can be used in the management of aphthous ulcers.
\end{abstract}

\section{INTRODUCTION}

Finding effective treatments for oral cancers, oral lichen planus and recurrent aphthous stomatitis (RAS) are among the most important challenges of oral medicine [1-4]. Recurrent aphthous stomatitis (RAS) is one of the most frequent oral diseases, and affects almost $20 \%$ of the population [5], but incidence varies from $5 \%$ to $50 \%$ depending on the groups under investigation and populations [6]. The cause of RAS is still unknown, as a result, it has no definitive pharmacological cure. Various topical agents are used in management of RAS. These include anesthetics (benzocaine), corticosteroids (dexamethasone, fluocinonide), antiseptics (chlorhexidine gluconate) and antibiotics (tetracycline,

\footnotetext{
* Corresponding authors

Dr. Hamid Reza Mozaffari

e-mail: mozaffari@kums.ac.ir; mozaffari20@yahoo.com

Dr. Reza Tahvilian

e-mail: rtahvilian@kums.ac.ir
}

minocycline) [7]. In this context, herbal medicine (plant extracts, essential oils and isolated compounds) has been proposed as the novel therapeutics [7] to provide effective and safer alternatives for RAS treatment.

Pomegranate (Punica granatum Linn), belongs to the Punicaceae family, and has been used from ancient times to confer health benefits with regard to a number of injuries and diseases [8]. The potential therapeutic properties of pomegranate are wide-ranging and include treatment of inflammatory conditions, cancer, cardiovascular disease, diabetes and dental conditions [8-10]. Almost all parts of a pomegranate have biological activities and are used in treatment [8]. Pomegranate peel (skin, rind or husk), is characterized by an interior network of membranes, and holds substantial amounts of beneficial phenolic compounds, including flavonoids (anthocyanins and catechins) and hydrolyzable tannins (punicalin, punicalagins, gallic acid and ellagic acid) 
[10-12]. The therapeutic potential of pomegranate peel has been widely recognized [8], for example, traditionally, aqueous pomegranate peel extract (PPE) obtained by boiling, has been used to treat dental plaque and aphthae $[8,13]$. Indeed, over the past few decades, scientific investigations have laid a credible basis for some of the traditional uses of the pomegranate peel.

Pomegranate peel has exhibited a high antioxidant potential. PPE and its bioactive ellagitannins (500-10,000 mg/L) have the ability to inhibit free radical generation in UVAand UVB-irradiated human skin, consequently protecting it from DNA damage [14]. PPE has been also demonstrated to inhibit inflammation and allergic reactions. The anti-inflammatory components of pomegranate, i.e., punicalagin and punicalin, significantly reduce production of nitric oxide and prostaglandin E2 $[15,16]$. Ouachrif et al. reported antiinflammatory properties of the PPE following intraperitoneal and intra-cerebroventricular administration in rats. The experiments indicated pain index reduction and a significant decrease in egg albumin induced hind paw inflammation [17].

Based on literature, two major factors involved in the incidence of RAS are the inflammatory responses and the reduction in antioxidative capacity. Cimen et al. [18] have reported a decrease in the enzymatic antioxidant capacity in patients with RAS. Karincaoglu et al. [19] found decreased glutathione peroxidase and other antioxidant enzymes levels in the saliva and serum of patients with RAS, in comparison with that in control subjects. In the matter of inflammation, studies confirmed that the disbalance between proinflammatory and anti-inflammatory cytokines may contribute to the formation of RAS. Indeed, Lewkowicz et al. [20] reported the enhanced production of proinflammatory cytokines and decreased anti-inflammatory cytokines by the peripheral blood mononuclear cells in RAS compared to the healthy controls.

Based on mentioned data, the present study was designed to study the efficacy of a topical form of PPE on RAS patients.

\section{MATERIALS AND METHODS}

This study was divided into two parts: laboratory procedures that involved the preparation of PPE topical gel and clinical trial that involved assessment of its effects on RAS patients.

\section{Preparation of PPE}

Fresh ripe pomegranate fruits were obtained from the local market in Kermanshah city, Iran. After washing, the peel (pericarp) and the pulp (mesocarp) of the fruit were separated from the seeds (endocarp). The plant material was dried in a greenhouse with air circulation, at room temperature for one week, followed by trituration in a cutting mill. The powder was stored in dark glass bottle until use. About $100 \mathrm{~g}$ of powdered peel material was added to a container containing one liter boiling distilled water. After about 20 min heating, the product was filtered through cotton plug and the residue was re-extracted in the same manner twice. The final concentration of PPE was 10\%.

\section{Preparation of topical gel}

PPE and placebo gels were made in our laboratory. The topical gels were prepared by mixing the distillated water, $0.5 \%$ carboxymethyl cellulose (CMC), $2 \%$ hydroxypropyl methylcellulose (HPMC), ascorbic acid as a preservative, and PPE. This combination was maintained with continuous stirring. The mixture was then poured immediately into aluminum tubes, capped and refrigerated at $4{ }^{\circ} \mathrm{C}$. The treatment gel finally consisted of $10 \%$ PPE. The formulation for the placebo gel was similar to that of the treatment gel, but without PPE, and with coloring agents (red and brown) to make it indistinguishable from the treatment gel in appearance.

\section{Quantification of total phenolics}

Total phenolics content of PPE gel was determined according to the colorimetric reaction of polyphenols with Folin-Ciocalteu reagent [21]. An aliquot $(1 \mathrm{~mL})$ of the extract was mixed with $5.0 \mathrm{~mL}$ of 10 -fold diluted Folin-Cio-

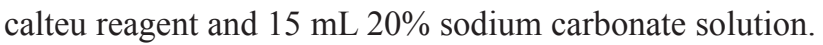
After $5 \mathrm{~min}$., the absorbance was measured using a UV-vis instrument at $750 \mathrm{~nm}$ and the total phenolic content was expressed as gallic acid equivalents (GAE) in mg per g dry material.

\section{Study Population}

In this double-blind, parallel, randomized clinical trial, 56 RAS patients were recruited from those referring to the Faculty of Dentistry at Kermanshah University of Medical Sciences, Kermanshah. At the screening visit, an experienced oral and maxillofacial medicine specialist diagnosed the RAS and specifications were recorded on patient charts. The following exclusion criteria were applied: smoking or alcoholism habits, pregnancy and lactation, orthodontic devices, a history of systemic disease that might impact the RAS pattern, drug usage or any local or systemic medications for RAS occurring in the past two months. The trial was registered in Iranian Registry of Clinical Trials (IRCT) with the ID number IRCT2016092414106N3. The protocol of this study was approved by the Clinical Research Ethics Committee of Kermanshah University of Medical Sciences. Written informed consent was obtained from all participants in the study prior to treatment. A clinician (clinician A) evaluated the parameters and an initial questionnaire was filled in. Clinician A was blinded when he was filling in the questionnaire for every patient. A record of the name, age, sex, duration of ulceration, size of ulcer (largest dimension of the ulcer) and pain of ulcer region was made. The patients were randomized in two groups: 28 patients were advised to apply PPE, and the other 28 patients, as control group, received placebo, twice daily for one week. The tubes containing PPE and placebo gels were similar in shape and size, and were randomly designated by letters A or B (A - treatment group and B - placebo group). The patients were followed up by clinician $\mathrm{B}$, who was unaware of the treatment administered. All the patients were blinded until the end of the study. Assessments were performed at days 0 (before using the oral gel), 3, 5 and 7 during one-week period of the study. Side effects were also 
monitored. The following clinical parameters were recorded and in both groups compared: ulcer size, pain of ulcer region and healing duration of ulcers. The size of the ulcers was assessed using a periodontal probe. The Visual Analog Scale (VAS) was used for assessment of pain intensity. Herein, the patients were asked to score the severity of pain on a 100-mm VAS, a 100-mm line labeled at one end as "no soreness" and the other end as "extremely soreness".

\section{Data analysis}

The results were analyzed using SPSS (version 18.0) and R software (version 3.2.2), by Independent samples t-test and Mann-Whitney U-test. The normal distribution of the data was evaluated by the Kolmogorov-Smirnov test. In all comparisons, $\mathrm{p}<0.05$ was considered as statistically significant.

\section{RESULTS}

The development of standardized herbal medicine requires one standardization product containing an active compound to be used as a marker. In regard to preparation of the topical form, the amount of total phenolics in PPE topical gel was determined with the Folin-Ciocalteu reagent. Figure 1 shows the contents of total phenols that were measured in terms of gallic acid equivalent.

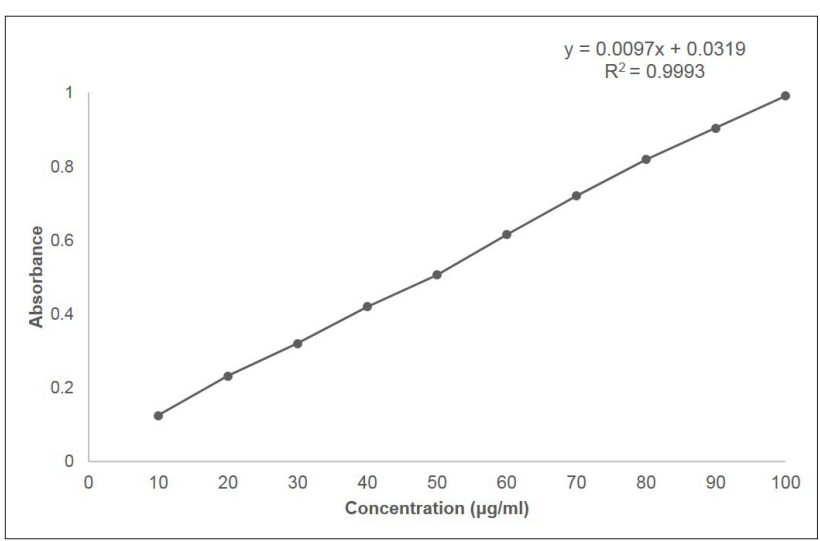

Figure 1. The contents of total phenols in PPE topical gel

A total of 56 RAS patients aged 19 to 42 years (mean age, 35.18) were enrolled in this study. After the beginning of the trial, no patient withdrawal occurred. There were no significant difference in terms of gender $(p=0.788)$ and age $(\mathrm{p}=0.827)$ between experimental and control groups (Table 1). There were no significant differences in ulcer size $(\mathrm{p}=0.889)$ and pain $(\mathrm{p}=0.286)$ between the two groups at the baseline (Table 2).

Table 1. Demographic information of the RAS patients

\begin{tabular}{|l|l|c|c|c|}
\hline \multicolumn{2}{|c|}{} & $\begin{array}{c}\text { Placebo } \\
(\text { Number (\%)) }\end{array}$ & $\begin{array}{c}\text { PPE } \\
(\text { Number (\%)) }\end{array}$ & p-value \\
\hline \multirow{2}{*}{ Sex } & Female & $16(57.1 \%)$ & $15(53.6 \%)$ & \\
\cline { 2 - 5 } & Male & $12(42.9 \%)$ & $13(46.4 \%)$ & \\
\hline $\begin{array}{l}\text { Age } \\
\text { (Mean } \pm \text { SD) }\end{array}$ & $35.54 \pm 2.81$ & $34.82 \pm 1.46$ & $0.827 *$ \\
\hline
\end{tabular}

* - Comparison between placebo and PPE groups by Independent sample t-test; SD - Standard deviation, age, year
Table 2. The mean values of ulcer size and pain of the RAS patients at baseline (before using the oral gel)

\begin{tabular}{|l|c|c|c|}
\hline & $\begin{array}{c}\text { Placebo } \\
(\text { Mean } \pm \text { SD) }\end{array}$ & $\begin{array}{c}\text { PPE } \\
(\text { Mean } \pm \text { SD })\end{array}$ & p-value* \\
\hline Ulcer size & $3.78 \pm 1.04$ & $3.74 \pm 1.05$ & 0.889 \\
\hline Pain & $84.46 \pm 10.66$ & $80.21 \pm 17.97$ & 0.286 \\
\hline
\end{tabular}

* - Comparison between placebo and PPE groups by Independent sample t-test; SD - Standard deviation; ulcer size, $\mathrm{cm}$; pain scale, $0-100$

The PPE group showed marked reduction in ulcer size at days $3(\mathrm{p}=0.001), 5(\mathrm{p}<0.001)$, and $7(\mathrm{p}=0.01)$ when compared to the placebo group (Table 3 ). The median values of ulcer size in the PPE group was significantly reduced to $1.98,0.42$, and 0.04 in days 3,5 and 7 after the intervention, respectively (Table 3 ).

Table 3. Comparison the ulcer size at days 0 (before using the oral gel), 3, 5 and 7 between the treatment of the two groups: PPE or placebo

\begin{tabular}{|l|c|c|c|}
\hline & $\begin{array}{c}\text { Placebo } \\
(\text { Mean } \pm \text { SD) }\end{array}$ & $\begin{array}{c}\text { PPE } \\
(\text { Mean } \pm \text { SD) }\end{array}$ & p-value* \\
\hline day 0 & $3.78 \pm 1.04$ & $3.74 \pm 1.05$ & 0.889 \\
\hline day 3 & $2.89 \pm 0.93$ & $1.98 \pm 0.94$ & 0.001 \\
\hline day 5 & $1.95 \pm 1.03$ & $0.42 \pm 0.63$ & $<0.001$ \\
\hline day 7 & $0.41 \pm 1.12$ & $0.04 \pm 0.19$ & 0.01 \\
\hline p-value & $<0.001$ & $<0.001$ & \\
\hline
\end{tabular}

* - Comparison between placebo and PPE groups by Independent sample t-test; $¥$ - Repeated-measures; SD, Standard deviation; ulcer size, cm

PPE was shown to be as effective with regard to reducing the pain of ulcer region (Table 4). In relation to the pain of ulcers, at the day 7, no patients in the PPE group had any pain $(p=0.01)$. The PPE group also showed significant improvement in the ulcer healing duration after treatment (Table 5). Compared with the placebo group, duration of ulcer healing decreased significantly from 7.09 to 4.91 days $(\mathrm{p}<0.001)$. None of the patients reported any irritation or other side effects at the site of application and other oral locations during interventions.

Table 4. Comparison of pain at days 0, 3, 5 and 7 between two treated groups: PPE or placebo

\begin{tabular}{|l|c|c|c|}
\hline & $\begin{array}{c}\text { Placebo } \\
\text { (Mean VAS } \pm \text { SD) }\end{array}$ & $\begin{array}{c}\text { PPE } \\
\text { (Mean VAS } \pm \text { SD) }\end{array}$ & p-value* \\
\hline day 0 & $84.46 \pm 10.66$ & $80.21 \pm 17.97$ & 0.286 \\
\hline day 3 & $59.46 \pm 13.22$ & $21.96 \pm 14.42$ & $<0.001$ \\
\hline day 5 & $38.04 \pm 21.79$ & $4.29 \pm 6.90$ & $<0.001$ \\
\hline day 7 & $4.82 \pm 9.18$ & 0 & 0.01 \\
\hline p-value & $<0.001$ & $<0.001$ & \\
\hline
\end{tabular}

* - Comparison between placebo and PPE groups by independent sample t-test; $¥$ - Repeated-measures; visual analog scale, 0 -100

Table 5. Results from comparing the ulcer healing duration between PPE and placebo groups after one-week period

\begin{tabular}{|l|c|c|c|}
\hline & Placebo & PPE & p-value* \\
\hline $\begin{array}{l}\text { Ulcer healing } \\
\text { duration } \\
\text { (Mean } \pm \text { SD) }\end{array}$ & $7.09 \pm 1.84$ & $4.91 \pm 1.16$ & $<0.001$ \\
\hline
\end{tabular}

t-test; SD - Standard deviation; ulcer healing duration, day 


\section{DISCUSSION}

Several symptomatic treatment modalities have been introduced to improve RAS symptoms. Most of these remedies are topical and are aimed at prevention of secondary infection, reduction of pain and inflammation, and at promoting ulcer healing. The most common topical agents are antiseptics (e.g., chlorohexidine, benzydamine, and doxycycline), anesthetics (e.g., benzocaine, lidocaine), corticosteroids (e.g., dexamethasone, triamcinolone) and immunomodulatory agents (e.g., amlexanox, colchicine, cyclosporine, cyclophosphamide, and methotrexate) [7]. However, all of these have side effects and risks that must be weighed against their benefits. There are obvious disadvantages in the use of broad-spectrum antibiotics for this purpose, the risk of hypersensitivity reactions and the growth of resistant organisms. Moreover, there is the possibility of systemic absorption due to prolonged use of topical corticosteroids [6]. As a consequence of the problems associated with chemical drugs, herbal agents can be considered as alternatives for the treatment of RAS. In this study, it was assumed that among a number of therapeutic benefits, the anti-inflammatory, antioxidant, and anti-microbial characteristics of PPE could be more advantageous in the management of aphthous ulcers.

Studies investigating the oxidative stress status in patients with RAS have been shown a decrease in the enzymatic antioxidant capacity $[18,19]$. In one such study, Saral et al. [23] demonstrated that the levels of selected antioxidant vitamins in serum and saliva are lower, while the lipid peroxidation and malondialdehyde (MDA) levels is higher in patients with RAS than in control subjects. Furthermore, results from a study on RAS patients by Arikan et al. [24] confirmed that glutathione peroxidase activities, vitamin $\mathrm{E}$ and selenium levels significantly decreased. Pomegranate peel, by holding valuable compounds including gallic acid, ellagic acid, ellagitanin, punicalagin, catechin and luteolin, has great antioxidant activity [8,25]. PPE was demonstrated in a rat study to have the antioxidant properties of enhancing or maintaining the free-radical scavenging activity of the hepatic enzymes: superoxide dismutase (SOD), catalase, and peroxidase. Nomura et al. revealed that mouth rinsing with pomegranate extract dissolved in water three times/day increased the levels of antioxidant enzymes and decreased activities of aspartate aminotransferase, an indicator of cell injury [26].

Pomegranate compounds, in that they have anti-inflammatory properties [8], may help to improve RAS symptoms. The results from Sastravaha et al. indicated that local delivery of PPE (in combination with Centellaasiatica) significantly improved clinical signs of chronic periodontitis [27]. They observed significant improvement in the periodontal parameters and a decrease in the pro-inflammatory effectors IL-1 $\beta$ and IL-6 at three and six months, compared to baseline [28]. Of note, TNF- $\alpha$ pro-inflammatory cytokine is believed to play an important role in the development of new ulcers, and has been found to be increased 2-5 fold in the saliva of RAS patients [29]. Decreased levels have also been reported in the SOD enzyme - a salivary defense system which participates in the inflammatory response of RAS [30].
PPE also have anti-bacterial and anti-fungal therapeutic effects on oral pathogens. The results of a randomized, double-blind study on sixty patients exhibited that pomegranate extract as a topical anti-fungal agent may be used for the treatment of candidosis associated with denture stomatitis and is as effective as miconazole, as a standard therapy. PPE gel was active against Streptococcus mutans, S. sanguisand $S$. mitis by controlling their adhesion potential to the surface in the oral cavity [31]. In this light, Batista et al. [32] conducted a randomized controlled clinical trial to evaluate the effectiveness of a mouthrinse with pomegranate and Matricaria recutita extracts, compared to $0.12 \%$ chlorhexidine in gingival bleeding subjects. The herbal mouthrinse were equally effective in alleviating this oral condition, producing anti-bacterial and anti-inflammatory properties similar to chlorhexidine.

Ghalayani et al. studied the efficacy of topical application of pomegranate hydroalcoholic extract for minor aphthous ulcer on 40 patients. They observed significant improvements, including reduction in pain and healing period compared to a placebo group [33]. In comparison to the present investigation, Ghalayani et al. [33] used Hydroalcholic solution of Pumegranate flower, but used water extract of the fruit peel by boiling water. In spite of similarities between flower and peel effective compounds, we aimed to assay the effects of native pomegranate of western region of Iran on RAS lesions and not the products of the Central region farms of Iran. In our work, in addition to period of RAS healing assessment, we assayed the effect of PPE on ulcer size in comparison with the Ghalayani and coworkers study.

We selected the $10 \%$ Gel concentration based on the study by Gavanji et al. [34] as they compared the effectiveness of different concentrations of Punica Gel on RAS patients. In the present work, the mean duration of ulcer healing was 7.09 days for the placebo group and 4.91 for the PPE group. The time period in Ghalayani [33] study was 5.3 days in the Pomegranate group and 8.6 days in the placebo group. The results of the study by Gavanji et al. [34] showed a mean healing time of 5.3 days for the Punica granatum group. The difference between two groups in the previous works $[33,34]$ and ours were statistically significant. Overall, however, these similar results confirm the potential healing of Pomegranate extracts.

The mean VAS score decreased from day 0 to day 7 for both groups and there was a significant difference between two groups in this regard. Comparing the result of the Mean VAS results of this study with that of Ghalayani et al. [33], indicates similarities in regard to significant differences between Pomegranate and Placebo groups in the different days of Gel application. Of interest, in our work, lesions in the PPE group have a lesser painful period ( 5 days) in comparison with 7 days in Ghalayani's study. In Gavanji's research, pain satisfaction difference between the Punica granatum and Placebo group, using non-parametric method was significant. Herein, they found that the water extract can relief pain more than alcoholic extract due to the irritating effect of alcohol [34].

About the safety of this formulation, we did not observe any adverse effects such as abscess, hypersensitivity or 
allergic reactions. Indeed, pomegranate juice, oil or peel extracts have been consumed for thousands of years without unexpected effects [10]. A research on 86 overweight human volunteers demonstrated the safety of pomegranate extract tablets in amounts up to $1.420 \mathrm{mg} /$ day for 28 days, no adverse changes reported in blood or urine laboratory values [35].

\section{CONCLUSION}

Parameters related to sample preparation and extraction process have key role in order to obtain a quality extract in terms of bioactive compounds such as polyphenol content. Furthermore, the type of solvents used and simplicity of methods need to be considered. We used simple, safe, and cost-benefit methods for preparation of this gel formulation. Our findings suggest that this 10\% topical PPE gel can be a useful and cost-effective option for management of RAS.

\section{PERSPECTIVE}

Pomegranate is native to Persia (Iran), Iran tops the list of world's pomegranate producers, in 2015, the total annual pomegranate production was 1 million tons; pomegranate peel comprises almost $26-30 \%$ of total fruit weight, thus generating 260,000-300,000 tons of agro-industrial residue which could have medicinal applications [8].

Supplementary information accompanies this paper at online version.

\section{ACKNOWLEDGEMENT}

\section{Compliance with ethical standards}

Financial support: The authors declare no competing financial interest.

Conflict of interest: The authors declare that they have no conflict of interest.

\section{ORCID iDs}

Sara Darakhshan (Dhttps://orcid.org/0000-0003-3611-7916 Fereshteh Bagheri (Dhttps://orcid.org/0000-0003-1737-9734 Mohsen Safaei (Dhttps://orcid.org/0000-0003-3885-6640 Roohollah Sharifi (Dhttps://orcid.org/0000-0001-7917-5409 Masoud Sadeghi (Dhttps://orcid.org/0000-0002-3586-3012 Masoud Hatami Dhttps://orcid.org/0000-0002-5739-9089 Hamid Reza Mozaffari (Dhttps://orcid.org/0000-0001-9351-1499 Reza Tahvilian Dhttps://orcid.org/0000-0001-6376-986X

\section{REFERENCES}

1. Mozaffari HR, Izadi B, Sadeghi M, Rezaei F, Sharifi R, Jalilian F. Prevalence of oral and pharyngeal cancers in Kermanshah province, Iran: A ten-year period. Int J Cancer Res. 2016;12(3-4):169-75.

2. Mozaffari HR, Payandeh M, Ramezani M, Sadeghi M, Mahmoudiahmadabadi M, Sharifi R. Efficacy of palifermin on oral mucositis and acute GVHD after hematopoietic stem cell transplantation (HSCT) in hematology malignancy patients: a metaanalysis of trials. Wspolczesna Onkol. 2017;21(4):299-305.

3. Mozaffari HR, Zavattaro E, Abdolahnejad A, Lopez-Jornet P, Omidpanah N, Sharifi R, Sadeghi M, Shooriabi M, Safaei M. Serum and salivary IgA, IgG, and IgM Levels in oral lichen planus: a systematic review and meta-analysis of case-control studies. Medicina 2018;54:99.

4. Preeti L, Magesh KT, Rajkumar K, Karthik R. Recurrent aphthous stomatitis. J Oral Maxillofac Pathol. 2011;15(3):252-6.
5. Chavan M, Jain H, Diwan N, Khedkar S, Shete A, Durkar S. Recurrent aphthous stomatitis: a review. J Oral Pathol Med. 2012;41: 577-83.

6. Rogers RS. Recurrent aphthous stomatitis: clinical characteristics and associated systemic disorders. Semin Cutan Med Surg. 1997;16: 278-83.

7. Belenguer-Guallar I, Jimenez-Soriano Y, Claramunt-Lozano A. Treatment of recurrent aphthous stomatitis. A literature review. J Clin Exp Dent. 2014;6:168-74.

8. Lansky EP, Newman RA. Punica granatum (pomegranate) and its potential for prevention and treatment of inflammation and cancer. J Ethnopharmacol. 2007;109:177-206.

9. Ismail T, Sestili P, Akhtar S. Pomegranate peel and fruit extracts: a review of potential anti-inflammatory and anti-infective effects. J Ethnopharmacol. 2012;143:397-405.

10. Jurenka J. Therapeutic applications of pomegranate (Punica granatum L.): a review. Altern Med Rev. 2008;13:128-44.

11. Afaq F, Saleem M, Krueger CG, Reed JD, Mukhtar H. Anthocyaninand hydrolyzable tannin-rich pomegranate fruit extract modulates MAPK and NF- $\kappa B$ pathways and inhibits skin tumorigenesis in CD-1 mice. Int J Cancer. 2005;113:423-33.

12. Negi PS, Jayaprakasha GK. Antioxidant and antibacterial activities of Punica granatum peel extracts. Food Microb Safety. 2003;68:1473-77.

13. Lansky E, Shubert S, Neeman I. Pharmacological and therapeutic properties of pomegranate. InSymposium on production, processing and marketing of pomegranate in the Mediterranean region: advances in research and technology. Semin Mediterraneens (CIHEAM). 2000; 231-5.

14. Pacheco-Palencia LA, Noratto G, Hingorani L, Talcott ST, MertensTalcott SU. Protective effects of standardized pomegranate (Punica granatum L.) polyphenolic extract in ultraviolet-irradiated human skin fibroblasts. J Agricultur Food Chem. 2003;56:8434-41.

15. Lee SI, Kim BS, Kim KS, Lee S, Shin KS, Lim JS. Immune-suppressive activity of punicalagin via inhibition of NFAT activation. Biochem Biophysic Res Communications. 2008;371:799-803.

16. Romier B, Van De Walle J, During A, Larondelle Y, Schneider YJ. Modulation of signalling nuclear factor- $\kappa \mathrm{B}$ activation pathway by polyphenols in human intestinal Caco-2 cells. Br J Nutr. 2008;100(3): 542-51.

17. Ouachrif A, Khalki H, Chaib S, Mountassir M, Aboufatima R, Farouk L, Benharraf A, Chait A. Comparative study of the antiinflammatory and antinociceptive effects of two varieties of Punica granatum. Pharm Biol. 2012;50(4):429-38.

18. Cimen MY, Kaya TI, Eskandari G, Tursen U, Ikizoglu G, Atik U. Oxidant/antioxidant status in patients with recurrent aphthous stomatitis. Clin Exp Dermatol. 2003;28:647-50.

19. Karincaoglu Y, Batcioglu K, Erdem T, Esrefoglu M, Genc M. The levels of plasma and salivary antioxidants in the patient with recurrent aphthous stomatitis. J Oral Pathol Med. 2005;34:7-12.

20. Lewkowicz N, Banasik M, Tchorzewski H, Kurnatowska AJ, Lewkowicz P. Predominance of Production of Th1 Type Cytokines in Recurrent Aphthous Ulceration. Dent Med Probl. 2004;42:655-60.

21. Gamez-Meza N, Noriega-Rodríguez JA, Medina-Juarez LA, OrtegaGarcía J, Cazarez-Casanova R, Angulo-Guerrero O. Antioxidant activity in soybean oil of extracts from Thompson grape bagasse. J American Oil Chem Society. 1999;76:1445-7.

22. Field EA, Allan RB. Oral ulceration - aetiopathogenesis, clinical diagnosis and management in the gastrointestinal clinic. Aliment Pharmacol Ther. 2003;18(10):949-62.

23. Saral Y, Coskun BK, Ozturk P, Karatas F, Ayar A. Assessment of salivary and serum antioxidant vitamins and lipid peroxidation in patients with recurrent aphthous ulceration. Tohoku J Exp Med. 2005;206:305-12.

24. Arikan S, Durusoy C, Akalin N, Haberal A, Seckin D. Oxidant/ antioxidant status in recurrent aphthous stomatitis. Oral Dis. 2009; 15:512-5.

25. Chidambara Murthy KN, Jayaprakasha GK, Singh RP. Studies on antioxidant activity of pomegranate (Punica granatum) peel extract using in vivo models. J Agric Food Chem. 2002;50:4791-5.

26. Nomura Y, Tamaki Y, Tanaka T, Arakawa H, Tsurumoto A, Kirimura K, et al. Screening of periodontitis with salivary enzyme tests. J Oral Sci. 2006;48:177-83. 
27. Sastravaha G, Yotnuengnit P, Booncong P, Sangtherapitikul P. Adjunctive periodontal treatment with Centella asiatica and Punica granatum extracts. A preliminary study. J Int Acad Periodontol. 2003; 4:106-15.

28. Sastravaha G, Gassmann G, Sangtherapitikul P, Grimm WD. Adjunctive periodontal treatment with Centella asiatica and Punica granatum extracts in supportive periodontal therapy. J Int Acad Periodontol. 2005;7(3):70-9.

29. Eguia-del Valle A, Martinez-Conde-Llamosas R, López-Vicente J, Uribarri-Etxebarria A, Aguirre-Urizar JM. Salivary levels of Tumour Necrosis Factor-alpha in patients with recurrent aphthous stomatitis. Med Oral Patol Oral Cir Bucal. 2011;16:33-6.

30. Momen-Beitollahi J, Mansourian A, Momen-Heravi F, Amanlou M, Obradov S, Sahebjamee M. Assessment of salivary and serum antioxidant status in patients with recurrent aphthous stomatitis. Med Oral Patol Oral Cir Bucal. 2010;15(4):557-61.

31. Vasconcelos LC, Sampaio MC, Sampaio FC, Higino JS. Use of Punica granatum as an antifungal agent against candidosis associated with denture stomatitis. Mycoses. 2003;46(5-6):192-6.
32. Batista AL, Lins RD, de Souza Coelho R, do Nascimento Barbosa D, Belém NM, Celestino FJ. Clinical efficacy analysis of the mouth rinsing with pomegranate and chamomile plant extracts in the gingival bleeding reduction. Complement Ther Clin Pract. 2014;20(1): 93-8.

33. Ghalayani P, Zolfaghary B, Farhad AR, Tavangar A, Soleymani B. The efficacy of Punica granatum extract in the management of recurrent aphthous stomatitis. J Res Pharm Pract. 2013;2:88-92.

34. Gavanji S, Larki B, Bakhtari A. The effect of extract of Punica granatum var. pleniflora for treatment of minor recurrent aphthous stomatitis. Integr Med Res. 2014;3(2):83-90.

35. Heber D, Seeram NP, Wyatt H, Henning SM, Zhang Y, Ogden LG, Dreher M, Hill JO. Safety and antioxidant activity of a pomegranate ellagitannin-enriched polyphenol dietary supplement in overweight individuals with increased waist size. J Agric Food Chem. 2007;55: 10050-4. 